\title{
Insulin Growth Factor-I in Protein-Energy Malnutrition during Rehabilitation in Two Nutritional Rehabilitation Centres in Burkina Faso
}

\author{
S. Kouanda, ${ }^{1}$ B. Doulougou, ${ }^{1}$ V. De Coninck, ${ }^{2}$ L. Habimana, ${ }^{3}$ B. Sondo, ${ }^{1}$ R. Tonglet, ${ }^{3}$ \\ J. M. Ketelslegers, ${ }^{2}$ and A. Robert ${ }^{3}$ \\ ${ }^{1}$ Institut de recherche en Sciences de la Santé, Centre national de la recherche Scientifique et Technologique, \\ Ministère des Enseignements Secondaire, Supérieur et de la Recherché Scientifique, BP 7192 Ouagadougou, Burkina Faso \\ ${ }^{2}$ Unité de Diabétologie et de Nutrition, Avenue Hippocrate 54, Bte 5474, 1200 Woluwe Saint Lambert, Brussels, Belgium \\ ${ }^{3}$ Unité d'épidémiologie, biostatistique et méthodes opérationnelles en santé publique, Clos Chapelle aux Champs, \\ 30, bte 3058, 1200 Woluwe-saint-Lambert, Brussels, Belgium
}

Correspondence should be addressed to S. Kouanda, skouanda@irss.bf

Received 2 November 2008; Accepted 15 January 2009

Recommended by Sasithon Pukrittayakamee

Objective. To investigate the relationship between IGF-I and the nutritional status of West-African children hospitalised for nutritional rehabilitation. Patients and methods. A cohort study was performed in two centres for nutritional rehabilitation and education (CREN) in Burkina Faso. Children were followed and the anthropometric data as well as the capillary blood samples were taken on the 7th and on the 14th days after their admission. IGF-I levels were determined from dried blood spots on filter paper on IGF-I RIA, after separation of the IGF-I from its binding proteins, using Sep-Pak chromatography. Results. A total of 59 children was included in the cohort. The IGF-I mean geometric values (SD) were $6.3(1.4) \mu \mathrm{g} / \mathrm{L}$ on admission, 8.6 (1.8) $\mu \mathrm{g} / \mathrm{L}$ at day 7 and $13.6(2.0) \mu \mathrm{g} / \mathrm{L}$ at day 14. The differences between these values were statistically significant $(P<.001)$. There is a significant correlation between the changes of IGF-I with the change of weight for height $\mathrm{Z}$-score $(P=.01)$. Conclusion. These results suggest that IGF-I can be considered as a potential marker to follow the nutritional status of children admitted in hospital for protein and energy malnutrition.

Copyright (C) 2009 S. Kouanda et al. This is an open access article distributed under the Creative Commons Attribution License, which permits unrestricted use, distribution, and reproduction in any medium, provided the original work is properly cited.

\section{Introduction}

Protein-energy malnutrition (PEM) remains a major public health problem in the world, particularly in developing countries. According to the World Health Organization (WHO), PEM affects one-third of children around the world, and $43 \%$ of children in developing countries (230 million), presenting a delay in staturoponderal growth [1]. In Burkina Faso, the prevalence of children with acute malnutrition is $19 \%$, while $39 \%$ present a delay of statural growth, and $38 \%$ have weight insufficiency [2].

The usual signs of children malnutrition are clinical signs and anthropometric measures. However, biological markers such as albumin, transthyretin, transferrin, and retinol binding protein are also used for nutritional diagnosis and rehabilitation aftercare. Several surveys have shown the relationship between clinical, anthropometric, or biological indicators and mortality of children suffering from PEM in hospitals [3-5].

More recently used markers like insulin-growth factorI (IGF-I) used to measure the deficit in growth hormone $(\mathrm{GH})$, and the insulin growth factors binding proteins (IGFBPs) also draw attention. Insulin-like growth factor-I (IGF-I) is single-chain peptides of 7.5 kilodaltons (kDas). Her structure is similar to the IGF-II and proinsulin $[6,7]$. The liver is believed to be the main source of production of IGF-I [8-10], but the highest concentrations of IGF-I are observed in blood $[11,12]$. IGF-I is also synthesized by several tissues $[13,14]$. 
Many factors intervene in the regulation of the IGF-I but the most important are growth hormone (GH), insulin, and nutritional status [15].

Nutritional status plays an important role in the regulation of the IGF-I. Adequate food intake is essential for maintaining normal IGF-I and IGFBP-3 circulating rates in the serum $[16,17]$. Indeed, energy and protein restrictions in children lead to a decrease of circulating IGF-I and IGFBP-3 rates [18].

The variations of serum IGF-I rates observed in response to different nutritional states suggest that IGF-I may serve as a marker for children nutritional state [19-21]. The IGF-I appears indeed as a marker potentially more sensitive than the serum albumin or the transferrin, even if the effect of infection on circulating concentration must be taken into account [22-24].

Only two surveys have been conducted on IGF-I and the nutritional rehabilitation among children under 5 years old but both were inconclusive because of low sample sizes $[22,24]$, but both were inconclusive because of low-sample sizes. These two studies did not also analyse the change of IGF-I and the changes of nutritional status. So, the purpose of our study is to analyse the relationship between the IGFI values and the nutritional status of children hospitalised for nutritional rehabilitation in the context of a West-African country.

\section{Patients and Methods}

The study of protocol was reviewed and approved by the Ethics Committee for Research in Health of Burkina Faso.

2.1. Subjects. This study was conducted in two nutritional rehabilitation centres: (CREN) of the regional hospital (CHR) and the Persis medical centre (CM) of the city of Ouahigouya, located in the northern part of Burkina Faso.

All consecutively admitted patients with PEM should be included in the study. Among these patients, the criteria for selection were the age $<60$ months and the absence of known pathology like HIV, diabetes, congenital diseases, and tumours.

Upon admission, social and demographic characteristics (age, sex, and vaccination past records) were collected; weight and height were measured, and different clinical data were checked (presence of oedema, coloration of hair, splenomegaly, and hepatomegaly). Then, a capillary blood sample was taken from the child finger. The children were followed up and the anthropometric data and the capillary blood samples were again taken again on the 7 th and the 14th days after admission.

The children admitted for malnutrition were well-cared for. They benefited from a free standard feeding which consisted of milk F75 for 7 days at $135 \mathrm{Kcal} / \mathrm{Kg}$ weight per day and milk F100 after the week at $100 \mathrm{Kcal} / \mathrm{Kg}$ weight per day. This posology was increased by $20 \mathrm{Kcal}$ every 3 days until $200 \mathrm{Kcal} / \mathrm{Kg}$ per day, as necessary. In addition, the children received enriched pulp five times a day. A treatment for
TABLE 1: Social and demographic characteristics of the household and the children admitted in two the nutritional rehabilitation centres in Burkina Faso.

\begin{tabular}{|c|c|c|}
\hline Social and demographic characteristics & $\mathrm{N}$ & Mean \pm SD or $\%$ \\
\hline \multicolumn{3}{|l|}{ Gender of the children } \\
\hline Boys & 37 & 62.7 \\
\hline Girls & 22 & 37.3 \\
\hline Mean age of children (months) & 59 & $14 \pm 6$ \\
\hline \multicolumn{3}{|l|}{ Age categories of children (months) } \\
\hline $0-5$ & 4 & 6.8 \\
\hline $6-11$ & 6 & 10.2 \\
\hline $12-23$ & 45 & 76.3 \\
\hline $24-35$ & 4 & 6.8 \\
\hline Age of the mothers & 56 & $27.3 \pm 6.1$ \\
\hline \multicolumn{3}{|l|}{ Age categories (years) } \\
\hline$\leq 19$ & 6 & 10.7 \\
\hline $20-24$ & 13 & 23.2 \\
\hline $25-29$ & 15 & 26.8 \\
\hline $30-34$ & 14 & 25.0 \\
\hline $35-39$ & 8 & 14.3 \\
\hline \multicolumn{3}{|l|}{ Scholarship of the mother } \\
\hline Yes & 2 & 3.4 \\
\hline No & 57 & 96.6 \\
\hline \multicolumn{3}{|l|}{ Scholarship of the father } \\
\hline Yes & 7 & 11.9 \\
\hline No & 52 & 88.1 \\
\hline \multicolumn{3}{|l|}{ Employment of the mother } \\
\hline Housewife & 55 & 93.2 \\
\hline Independents/employees & 4 & 6.8 \\
\hline \multicolumn{3}{|l|}{ Employment of the father } \\
\hline Farmer & 52 & 88.1 \\
\hline Independent/employees & 7 & 11.9 \\
\hline
\end{tabular}

bacterial infections and malaria was available at any time if required.

A total of 68 children were recruited for the study but only 59 were included because the ages of 9 children were unknown. Table 1 shows the sociodemographic characteristics of the 59 children. The sex ratio was 1.68 for boys; $76.3 \%$ of the children were aged between 1 and 2 years. Most of the mothers (96.6\%) and the fathers $(88.1 \%)$ had no scholarship education. Mothers were mainly housewives and fathers were mainly farmers. With regard to vaccine status, two thirds of the children were fully vaccinated, $30.9 \%$ not fully vaccinated, and $3.6 \%$ were not vaccinated at all. The average maternal breast-feeding duration was $9 \pm 3$ months.

2.2. Evaluation of Nutritional Status. Weight and height were determined on a Salter balance and the height was rounded to the nearest centimetre. For children younger than 2 years, height (length) was measured on a supine table as follows: an assistant held the head against the headboard and another straightened the legs. For children older than 2 years, a stadiometer was used. Nutritional status, expressed 
as weight for height (WHZ) and height for age (HAZ), was standardised for age and sex using either the reference tables from the Burkina Faso reference tables [25] or the United States National Center for Health Statistics (NCHS) [26, 27]. The reference tables of Burkinabe children were constructed from anthropometric measures collected during the survey on the reference values of IGF-I in Burkina Faso [25].

2.3. Blood Sampling. Blood was obtained by vein puncture and 2 drops per circle were immediately collected on (free falling) the filter paper; 2 circles per paper were systematically filled; the samples were dried after 5-10 minutes at ambient temperature $\left(30-35^{\circ} \mathrm{C}\right)$ and were kept at $4^{\circ} \mathrm{C}$ for $1-2$ weeks before processing.

All filter paper samples were transferred for analyses to the Unit of Diabetes and Nutrition, Belgium. Samples were collected between October 2005 and May 2006.

2.4. Sample Processing and IGF-I Assay. We validated the methods of determining the IGF-I levels from dried blood spots on filter paper on IGF-I RIA, after separating the IGFI from its binding proteins using Sep-Pack chromatography [25].

The extraction recovery of IGF-I was of $84.4 \pm 3.4 \%$. IGFI was determined by RIA, using the antiserum at a 1/15000 dilution, and ${ }^{125}$ I- IGF-I was labeled by the iodogene method and purified by RP-HPLC. The concentration of the standard curve spans over a range of 0.05 to $2 \mathrm{ng} / \mathrm{mL}$. Intra-assay and total imprecision of the RIA were of $5 \%$ and $16 \%$ at a level of $0,25 \mathrm{ng} / \mathrm{mL}$ and of $5 \%$ and $22 \%$ at a level of $1.01 \mathrm{ng} / \mathrm{mL}$ [25].

IGF-I absolute measurements were also standardised for age and sex, and reported as IGF-I $Z$ scores, using the reference values of IGF-I in children from birth to the age of 5 in Burkina Faso [25].

2.5. Statistical Methods. Results are expressed as proportions for discrete variables, as means and standard deviations (SDs) for continuous variables with a normal distribution, and as geometric means with geometric standard deviations for continuous variables with a log-normal distribution, like IGF-I. Standardised values are expressed as Z-scores and are reported as mean $\pm \mathrm{SD}$ and proportion under -2.00 or under -3.00 . IGF-I was considered either as an absolute measurement and analysed on a log scale, or as an ageand sex-adjusted normal Z-score and analysed on a linear scale. Relationships between IGF-I and WHZ at baseline and after 14 days of nutritional rehabilitation were assessed using $r$, the Pearson cross-product correlation coefficient. Changes in IGF-I after 14 days of nutritional rehabilitation were expressed as ratio for absolute measurements and as differences for standardised values, and changes were tested using Student's paired $t$-test. Relationships between changes in IGF-I and increases in WHZ were assessed using also $r$. No $P$-value was corrected for multiple comparisons and a $P$ value $<.05$ was considered as statistically significant. Statistical analyses were performed using SPSS 15.0 software.

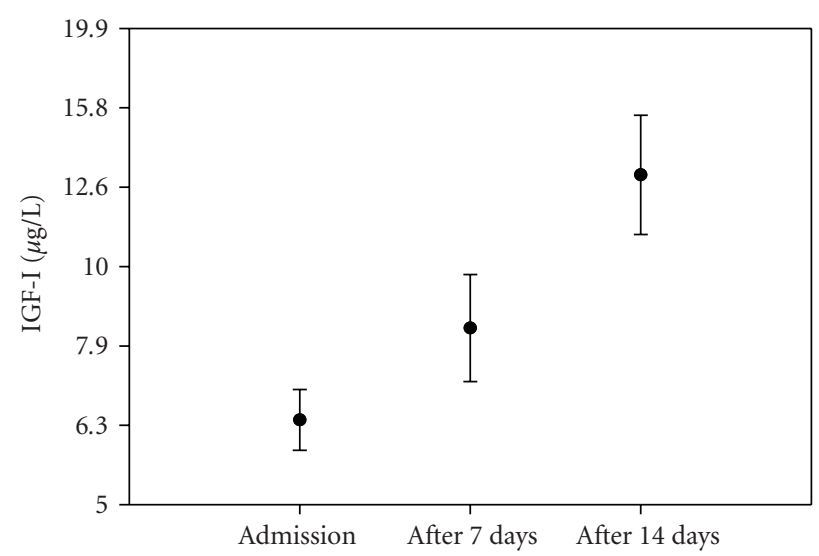

FIGURE 1: Increase in IGF-I during nutritional rehabilitation in 59 children admitted for malnutrition in Burkina Faso.

\section{Results}

3.1. Evaluation of the Nutritional Status and IGF-I Values of Children upon Admission and during Rehabilitation. Two children (3.4\%) were admitted to the Nutritional Rehabilitation Centre because of kwashiorkor, 55 children (93.2\%) were admitted for marasmus, and two presented with both kwashiorkor and marasmus. One child died during the follow-up.

At the time of admission, using international reference values as standards, 57 children $(96.6 \%)$ had an age- and sex-adjusted weight for height Z-score lower than -2.0 , including 43 children with a WHZ $<-3.0$. Three children presented oedemas at admission and their WHZ was lower than -2.0 .

Out of the 57 children with a WHZ $<-2.0,51(89.5 \%)$ had also an age- and sex- adjusted IGF-I Z-score of $<-2.0$. An IGF-I Z score of $<-2.0$ was also observed in $90.7 \%(39 / 43)$ of children presenting with a $\mathrm{WHZ}<-3.0$.

When using Burkina Faso age and sex reference values for standardising, $44 \%(26 / 59)$ of children had a WHZ $<-2.0$, and $8 \%(5 / 59)$ had a WHZ $<-3.0$. The proportion of IGFI Z-score of $<-2.0$ was $89 \%(23 / 26)$ in children with WHZ $<-2.0$ and $80 \%(4 / 5)$ in children with WHZ $<-3.0$.

After 14 days of nutritional rehabilitation, 22 children (37\%) reached a WHZ $\geq-2.0$ according to international references, and $91 \%$ of these children (20/22) also attained an IGF-I Z-score $\geq-2.0$. Using Burkina Faso data as standards, the WHZ was $\geq-2.0$ in $80 \%(n=47)$ of children after 14 days of nutritional rehabilitation, and $81 \%$ of these children $(n=38)$ also reached an IGF-I Z-score $\geq-2.0$, suggesting a quick recovery of IGF-I, as illustrated in Figure 1.

During nutritional rehabilitation, IGF-I increased from $6.36(1.40) \mu \mathrm{g} / \mathrm{L}$ (geometric mean and SD) upon admission, to $8.59(1.81) \mu \mathrm{g} / \mathrm{L}$ after one week, and to $13.65(2.0) \mu \mathrm{g} / \mathrm{L}$ after two weeks of nutritional rehabilitation (Figure 1).

Table 2 shows the parallel increase in weight and in IGF-I, from admission to 7 and 14 days after nutritional rehabilitation. Data are presented as absolute measurements, as standardised measurements using international references 
TABLE 2: Weight for height and IGF-I increase during nutritional rehabilitation, in 59 malnourished children in Burkina Faso.

\begin{tabular}{|c|c|c|c|c|}
\hline \multirow[t]{2}{*}{ Absolute measurements } & & Weight $(\mathrm{kg})$ & & IGF-I ratio to admission \\
\hline & $n$ & Mean $\pm \mathrm{SD}$ & $n$ & [95\% confidence interval] \\
\hline Admission & 59 & $5.520 \pm 1.003$ & 59 & 1 \\
\hline After 7 days & 59 & $5.943 \pm 1.022$ & 59 & $1.59[1.29 ; 1.89]$ \\
\hline After 14 days & 59 & $6.362 \pm 1.143$ & 59 & $2.52[2.10 ; 2.94]$ \\
\hline \multicolumn{5}{|c|}{ Age- and sex-adjusted ${ }^{*}$ weight for height Z-score } \\
\hline & $n$ & Mean \pm SD & & \\
\hline Admission & 59 & $-3.56 \pm 0.85$ & & \\
\hline After 7 days & 59 & $-3.05 \pm 0.79$ & & \\
\hline After 14 days & 59 & $-2.44 \pm 1.06$ & & \\
\hline \multicolumn{3}{|c|}{ Age- and sex-adjusted ${ }^{* *}$ weight for height $\mathrm{Z}$-score } & & IGF-I Z-score \\
\hline & $n$ & Mean \pm SD & $n$ & Mean \pm SD \\
\hline Admission & 59 & $-1.87 \pm 0.89$ & 59 & $-2.55 \pm 0.80$ \\
\hline After 7 days & 59 & $-1.45 \pm 0.90$ & 59 & $-2.03 \pm 1.22$ \\
\hline After 14 days & 59 & $-1.07 \pm 1.02$ & 59 & $-1.16 \pm 1.39$ \\
\hline
\end{tabular}

Reference values from Burkina Faso.

$* *$ International reference values.

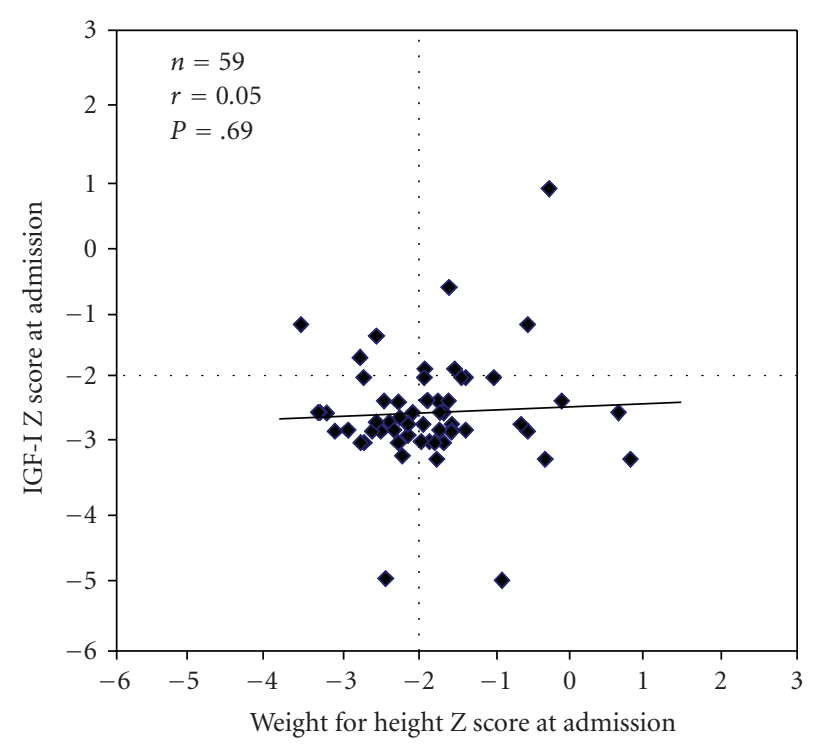

(a)

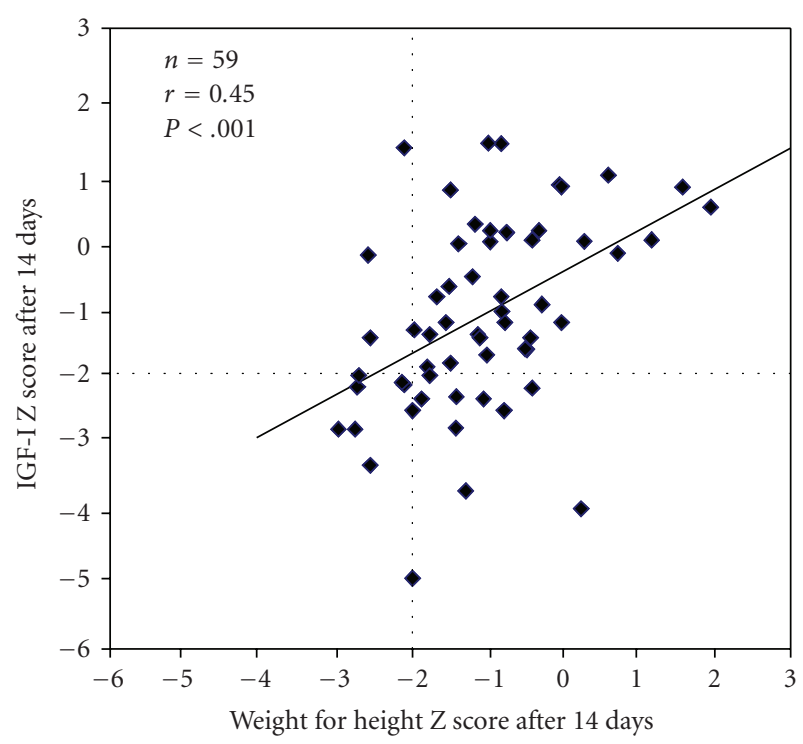

(b)

FIGURE 2: Relationship between age- and sex-adjusted IGF-I Z-score and weight for height Z-score with Burkina Faso data as references, at admission and after 14 days of nutritional rehabilitation in 59-malnourished children from Burkina Faso.

for age and sex adjustments, and as standardised measurements using Burkina Faso data as standards.

After 7 days of nutritional rehabilitation, IGF-I was multiplied by 1.587 , as a significant increase of $58.7 \%$ on average. After 14 days, IGF-I increase was about $151.8 \%$ on average.

There was a significant increase in log-scaled IGF-I, as well as in IGF-I Z-scores one week after admission (paired $t$ test, $P=.003$, and $P=.007$ ), and two weeks after admission (paired $t$-test, $P<.001$, and $P=.001$ ). A significant increase was also observed for weight for height Z-scores, with both standardisations.

The relationship between age- and sex-adjusted IGF-I score and weight for height Z-score using the Burkina Faso reference for standardisation is illustrated in Figure 2, upon admission (a) and after 14 days (b).

Upon admission, the proportion of children who had both WHZ of $<-2.0$ and IGF-I $Z$ score $<-2.0$ was $39 \%(23 / 59)$, but $47 \%(28 / 59)$ - a high proportion of children-had an IGF-I Z score of $<-2.0$ and WHZ of 


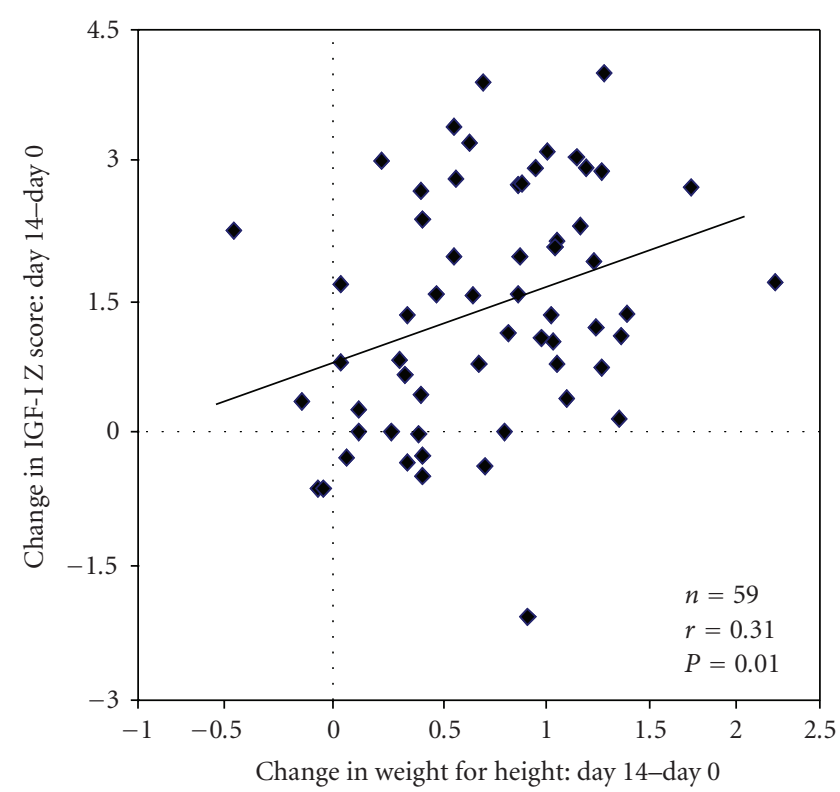

(a)

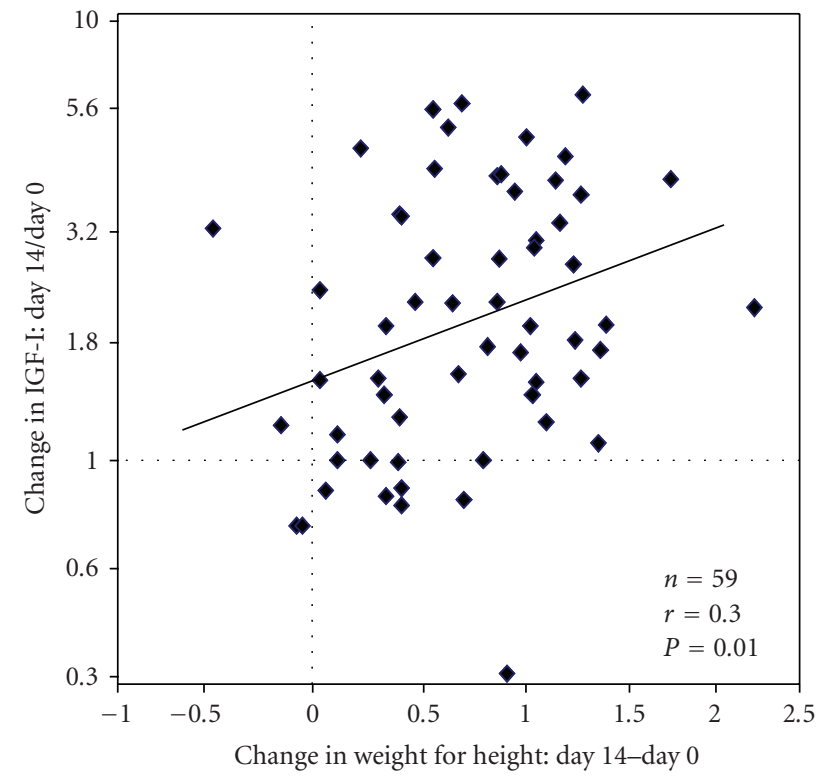

(b)

FIGURE 3: Relationship between the change in IGF-I expressed as an increase in Z-score (a) or as a ratio in absolute measurements (b) and the change in age- and sex-adjusted weight for height Z-score using Burkina Faso data as references, after 14 days of nutritional rehabilitation.

$\geq-2.0$, leading to a low correlation $(P=.69)$. After 14 days of nutritional rehabilitation, the proportion of children who both had WHZ $\geq-2.0$ and IGF-I $Z$ score of $\geq-2.0$ increased $64 \%$ (38/59), with highly significant correlation, as reflected in Figure 2(b).

Expressing the change in IGF-I as a difference in IGF-I Z scores or expressing the change in IGF-I as a ratio between IGF-I value after 14 days and IGF-I value upon admission, there was significant correlation with the increase in weight for height Z-scores $(P<.01$ on Figure 3(a), and $P<.01$ on Figure 3(b), resp.).

When using the international NCHS references for standardisation, there was an even higher correlation between changes in IGF-I and increases in weight for height Z-scores, with $r=0.38(P<.003)$ for differences in IGF-I Z scores, and $r=0.39(P<.003)$ for IGF-I absolute value ratios.

\section{Discussion}

The objective of this study was to assess the relationship between the IGF-I values and the nutritional status of children hospitalised for nutritional rehabilitation. The study also sought to determine IGF-I values as forecast markers of mortality. However, this last objective has not been achieved because the care given to children admitted in rehabilitation helped maintain a low mortality rate ( 1 in 68 children enrolled in the present study).

One of the limitations of our study is that the influence of factors like infection was not taken in consideration. The acute or chronic inflammatory status could interfere on the rate of IGF-I production. It was shown that in the experimental model, the stimulation of an inflammatory status by injection of endotoxin leads to a reduction of IGF-I rates due to a resistance of the GH [20]. During the sepsis, Yumet et al. observed an increase of $\mathrm{GH}$ with a reduction of $40-50 \%$ of plasma IGF-I in rat at 12 hours and 24 hours after $\mathrm{GH}$ administration [28].

As far as the evaluation of nutritional status is concerned, most of our patients suffered from protein and energy malnutrition, with a few cases of kwashiorkor. Using NCHS references, only two children had a WHZ $\geq-2.0$ at admission, and $73 \%$ presented severe malnutrition (WHZ $<-3$ ). When using local references, $56 \%$ of children had a WHZ $\geq-2.0$ at admission, and only $8 \%$ presented severe malnutrition. Of course, malnutrition is better defined using NCHS references than local ones in a developing country such as Burkina Faso. But both references were used to standardise nutritional status in our study because age and sex reference values for IGF-I were available at the local level only.

We observed variations of IGF-I with respect to the nutritional rehabilitation. Low IGF-I values were observed in hospital children suffering from protein and energy malnutrition $[22,23]$. But values were lower in children suffering from marasmus than in children suffering from kwashiorkor; this suggests that the secretion of IGF-I is closely related to energy consumption than to protein consumption [22]. After the nutritional rehabilitation of children admitted for protein and energy malnutrition, the IGF-I increased significantly in children that had kwashiorkor or marasmus. But the IGF-I values after 14 days of nutritional rehabilitation were still lower than in healthy children [22, 23]. There was no good agreement between the IGF-I values and the weight for height Z-scores upon admission, owing to the fact that a severe malnutrition was present in $73 \%$ of children and IGF-I values were too low to allow for correlation. But 
after 14 days, we observed good agreement between IGF-I values and WHZ values; the increase in IGF-I also paralleled the increase in weight for age $\mathrm{Z}$-scores. These results suggest that IGF-I can be a dynamic indicator of nutritional recovery.

The study conducted in Gabon by Zamboni et al. [22] reported IGF-I values of $2.7 \pm 0.7 \mathrm{nmol} / \mathrm{L}$ upon admission of 9 children (mean age: $17.2 \pm 5.4$ months) with kwashiorkor and the IGF-I increased to $7.6 \pm 1.7 \mathrm{nmol} / \mathrm{L}$ after $4-8$ weeks of nutritional rehabilitation. In children with marasmus $(n=$ 13), the values of IGF-I were $1.6 \pm 0.4 \mathrm{nmol} / \mathrm{L}$ on admission and $5.2 \pm 1.1 \mathrm{nmol} / \mathrm{L}$ after complete nutritional rehabilitation [22].

Palacio et al. [24] found that IGF-I concentrations increased significantly after $10 \%$ weight recovery in malnourished children $(n=15)$. On admission, the IGF-I values were $3.5 \pm 1.0 \mathrm{ng} / \mathrm{mL}$ and reached $5.9 \pm 2.0 \mathrm{ng} / \mathrm{mL}$ after $10 \%$ body weight gain [22].

Bhutta et al. [23] and Palacio et al. [24] reported that an increase in IGF-I rates in malnourished children and its relation with weight gain was observed during the rehabilitation. This was not observed for markers such as prealbumin or serum albumin $[23,24]$.

Smith et al. [29] observed that the caloric restriction induced a reduction in IGF-I and IGFBP-3 in adults and children. After nutritional rehabilitation, an increase was achieved, but without reaching the initial rates. A reduction in IGF-I rates was also reported in other types of malnutrition such as mental anorexia, coeliac, acquired immune deficiency syndrome (AIDS), or Crohn's disease [30, 31].

The ability of IGF-I to follow variations of nutritional status shows that it is potentially a good clinical marker to follow nutritional rehabilitation in children with protein and energy malnutrition. The prognostic interest of IGFI remains to be demonstrated by the implementation of studies which will measure the impact of IGF-I on the mortality of children with malnutrition in comparison with other markers of nutrition like albumin, prealbumin, and RBP. If the prognostic interest of IGF-I were proved, the use of IGF-I will be recommended. The experience shows that the cost of technology could be reduced quickly with the development of the research.

\section{Acknowledgments}

This research was supported by grants from Fonds de la Recherche Scientifique Médicale (convention FRSM 3.4561.04) and the Belgian Coopération Universitaire pour le Développement (CUD). The authors also thank Dr. Lassana Zalla of "Centre Medical Persis" and the paediatric staff of CHR of Ouahigouya.

\section{References}

[1] M. De Onis, C. Monteiro, J. Akré, and G. Clugston, "The worldwide magnitude of protein-energy malnutrition: an overview from the WHO global database on child growth," Bulletin of the World Health Organization, vol. 71, no. 6, pp. 703-712, 1993.
[2] Institut National de la Statistique et de la Démographie, Macro International Inc., Enquête Démographique et de Santé, 2003.

[3] A. Briend, C. Dykewicz, K. Graven, R. N. Mazumder, B. Wojtyniak, and M. Bennish, "Usefulness of nutritional indices and classifications in predicting death of malnourished children," British Medical Journal, vol. 293, no. 6543, pp. 373-375, 1986.

[4] J.-P. Beau, M. Garenne, B. Diop, A. Briend, and I. Diop Mar, "Diarrhoea and nutritional status as risk factors of child mortality in a Dakar hospital (Senegal)," Journal of Tropical Pediatrics, vol. 33, no. 1, pp. 4-9, 1987.

[5] M. Dramaix, D. Brasseur, P. Donnen, et al., "Prognostic indices for mortality of hospitalized children in Central Africa," American Journal of Epidemiology, vol. 143, no. 12, pp. 12351243, 1996.

[6] W. H. Daughaday and P. Rotwein, "Insulin-like growth factors I and II. Peptide, messenger ribonucleic acid and gene structures, serum, and tissue concentrations," Endocrine Reviews, vol. 10, no. 1, pp. 68-91, 1989.

[7] R. E. Humbel, "Insulin-like growth factors I and II," European Journal of Biochemistry, vol. 190, no. 3, pp. 445-462, 1990.

[8] P. McConaghey and C. B. Sledge, "Production of "sulphation factor" by the perfused liver," Nature, vol. 225, no. 5239, pp. 1249-1250, 1970.

[9] L. L. Miller, D. S. Schalch, and B. Draznin, "Role of the liver in regulating somatomedin activity: effects of streptozotocin diabetes and starvation on the synthesis and release of insulinlike growth factor and its carrier protein by the isolated perfused rat liver," Endocrinology, vol. 108, no. 4, pp. 1265$1271,1981$.

[10] J. C. Schwander, C. Hauri, J. Zapf, and E. R. Froesch, "Synthesis and secretion of insulin-like growth factor and its binding protein by the perfused rat liver: dependence on growth hormone status," Endocrinology, vol. 113, no. 1, pp. 297-305, 1983.

[11] R. W. Furlanetto, L. E. Underwood, J. J. Van Wyk, and A. J. D'Ercole, "Estimation of somatomedin-C levels in normals and patients with pituitary disease by radioimmunoassay," The Journal of Clinical Investigation, vol. 60, no. 3, pp. 648-657, 1977.

[12] J.-P. Thissen, J.-M. Ketelslegers, and L. E. Underwood, "Nutritional regulation of the insulin-like growth factors," Endocrine Reviews, vol. 15, no. 1, pp. 80-101, 1994.

[13] M. M. Rechler and S. P. Nissley, "The nature and regulation of the receptors for insulin-like growth factors," Annual Review of Physiology, vol. 47, pp. 425-442, 1985.

[14] J. J. Van Wyk, "The somatomedins: biological actions and physiological control mechanisms," in Hormonal Proteins and Peptides, C. H. Li, Ed., pp. 81-125, Academic Press, New York, NY, USA, 1984.

[15] J.-P. Thissen, L. E. Underwood, and J.-M. Ketelslegers, "Regulation of insulin-like growth factor-I in starvation and injury," Nutrition Reviews, vol. 57, no. 6, pp. 167-176, 1999.

[16] D. R. Clemmons, A. Klibanski, L. E. Underwood, et al., "Reduction of plasma immunoreactive somatomedin-C during fasting in humans," The Journal of Clinical Endocrinology \& Metabolism, vol. 53, no. 6, pp. 1247-1250, 1981.

[17] W. L. Isley, L. E. Underwood, and D. R. Clemmons, "Changes in plasma somatomedin- $\mathrm{C}$ in response to ingestion of diets with variable protein and energy content," Journal of Parenteral and Enteral Nutrition, vol. 8, no. 4, pp. 407-411, 1984.

[18] W. J. Smith, L. E. Underwood, and D. R. Clemmons, "Effects of caloric or protein restriction on insulin-like growth factor-I (IGF-I) and II concentrations and growth hormone 
and insulin responses to arginine infusion in children with protein-energy malnutrition before and after nutritional rehabilitation," Pediatric Research, vol. 20, pp. 1122-1130, 1995.

[19] J.-M. Ketelslegers, D. Maiter, M. Maes, L. E. Underwood, and J.-P. Thissen, "Nutritional regulation of the growth hormone and insulin-like growth factor-binding proteins," Hormone Research, vol. 45, no. 3-5, pp. 252-257, 1996.

[20] D. Defalque, N. Brandt, J.-M. Ketelslegers, and J.-P. Thissen, "GH insensitivity induced by endotoxin injection is associated with decreased liver GH receptors," American Journal of Physiology, vol. 276, no. 3, part 1, pp. E565-E572, 1999.

[21] L. E. Underwood, J.-P. Thissen, S. Lemozy, J.-M. Ketelslegers, and D. R. Clemmons, "Hormonal and nutritional regulation of IGF-I and its binding proteins," Hormone Research, vol. 42, no. 4-5, pp. 145-151, 1994.

[22] G. Zamboni, D. Dufillot, F. Antoniazzi, R. Valentini, D. Gendrel, and L. Tatò, "Growth hormone-binding proteins and insulin-like growth factor-binding proteins in protein-energy malnutrition, before and after nutritional rehabilitation," Pediatric Research, vol. 39, no. 3, pp. 410-414, 1996.

[23] Z. A. Bhutta, P. Bang, E. Karlsson, L. Hagenäs, S. Q. Nizami, and O. Söder, "Insulin-like growth factor I response during nutritional rehabilitation of persistent diarrhoea," Archives of Disease in Childhood, vol. 80, no. 5, pp. 438-442, 1999.

[24] A. C. Palacio, F. Pérez-Bravo, J. L. Santos, L. Schlesinger, and F. Monckeberg, "Leptin levels and IgF-binding proteins in malnourished children: effect of weight gain," Nutrition, vol. 18 , no. 1, pp. 17-19, 2002.

[25] S. Kouanda, R. Tonglet, V. De Coninck, et al., "Reference values of IGF-I in children from birth to 5 years of age, in Burkina Faso, using blood samples on filter paper," Growth Hormone \& IGF Research, vol. 18, no. 4, pp. 345-352, 2008.

[26] M. J. Dibley, J. B. Goldsby, N. W. Staehling, and F. L. Trowbridge, "Development of normalized curves for the international growth reference: historical and technical considerations," The American Journal of Clinical Nutrition, vol. 46, no. 5, pp. 736-748, 1987.

[27] OMS, "Utilisation et interprétation de l'anthropométrie," Série de Rapports Techniques 854, Organisation Mondiale de la Santé, Genève, Switzerland, 1995.

[28] G. Yumet, M. L. Shumate, D. P. Bryant, C. H. Lang, and R. N. Cooney, "Hepatic growth hormone resistance during sepsis is associated with increased suppressors of cytokine signaling expression and impaired growth hormone signalling," Critical Care Medicine, vol. 34, no. 5, pp. 1420-1427, 2006.

[29] W. J. Smith, L. E. Underwood, and D. R. Clemmons, "Effects of caloric or protein restriction on insulin-like growth factor-I (IGF-I) and IGF-binding proteins in children and adults," The Journal of Clinical Endocrinology \& Metabolism, vol. 80, no. 2, pp. 443-449, 1995.

[30] K. K. Hill, D. B. Hill, M. P. McClain, L. L. Humphries, and C. J. McClain, "Serum insulin-like growth factor-I concentrations in the recovery of patients with anorexia nervosa," Journal of the American College of Nutrition, vol. 12, no. 4, pp. 475-478, 1993.

[31] D. H. Sullivan and W. J. Carter, "Insulin-like growth factor I as an indicator of protein-energy undernutrition among metabolically stable hospitalized elderly," Journal of the American College of Nutrition, vol. 13, no. 2, pp. 184-191, 1994. 


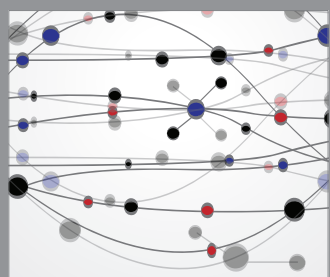

The Scientific World Journal
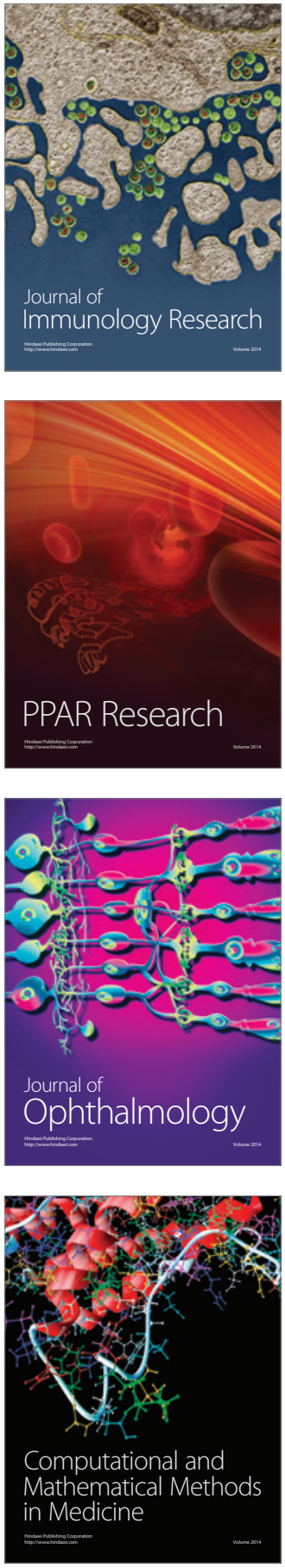

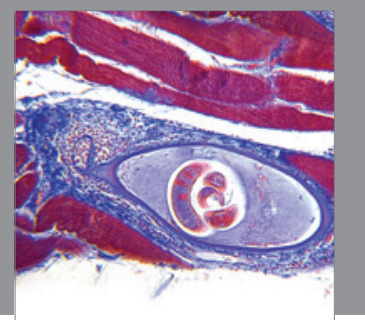

Gastroenterology

Research and Practice
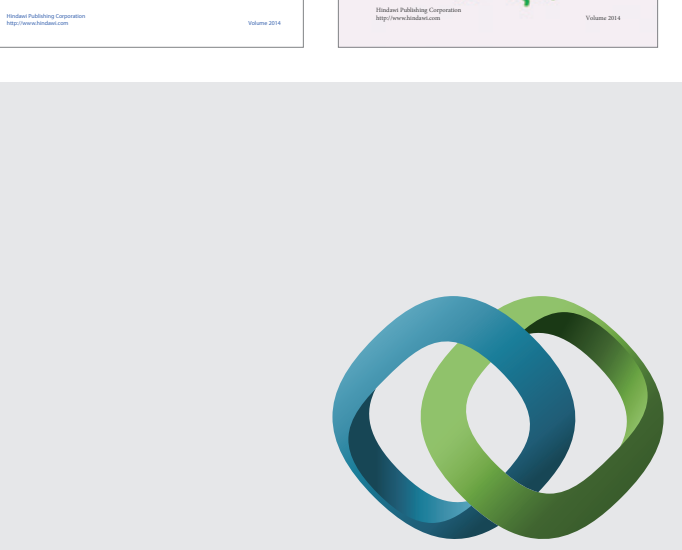

\section{Hindawi}

Submit your manuscripts at

http://www.hindawi.com
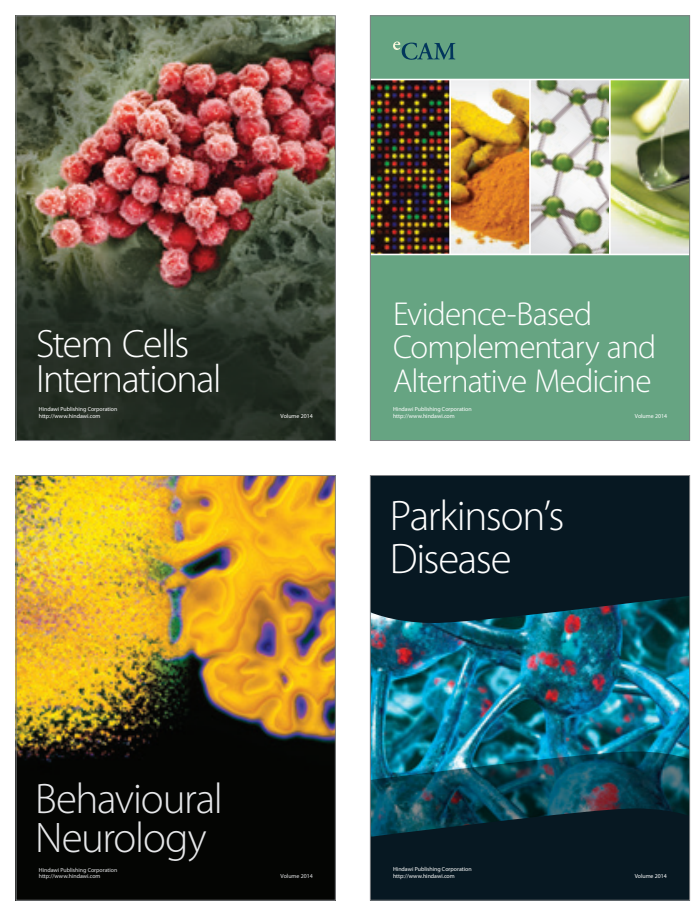

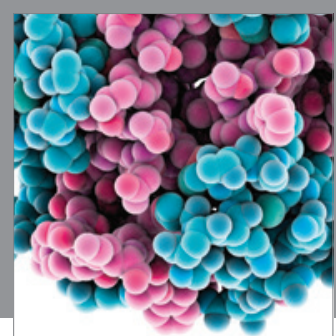

Journal of
Diabetes Research

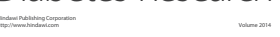

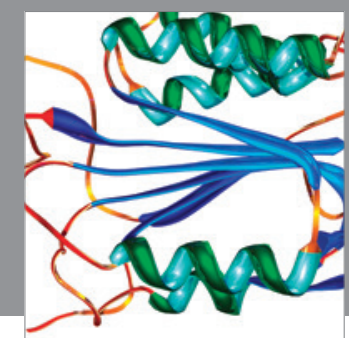

Disease Markers
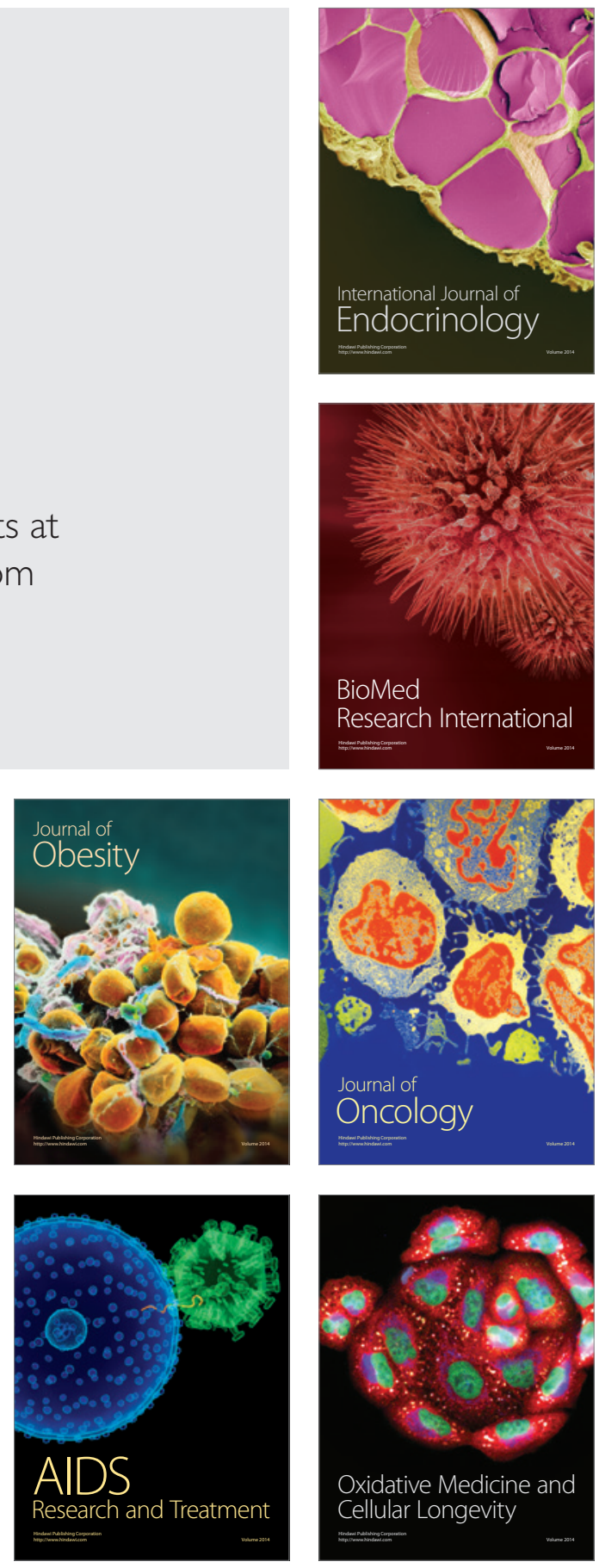